Short letter

\title{
In vivo exposure of a schizophrenic patient with agoraphobic symptoms
}

Sir: Although in vivo exposure has been reported as an effective treatment for phobias (Emmelkamp et al, 1979; Barlow et al, 1981), to our knowledge, there has been no report on the use of this technique for schizophrenic patients with phobic-like symptoms.

Mr L, aged 24 years, meeting DSM III criteria for undifferentiated schizophrenia, was referred to our out-patient clinic in the summer of 1987.

Four years ago, whilst a college student with no previous psychiatric history, agoraphobic-like symptoms appeared and became rapidly incapacitating. Anxiety was very marked in streets and public places, but unlike DSM III agoraphobics, the patient did not fear faintness or lack of first-aid, but assault from passers-by. He dropped out of college and became progressively very withdrawn, stayed home and avoided social contacts, went out on short stereotyped trips only if accompanied by a relative. In 1986 he suffered an acute delirious episode with auditory hallucinations with a bizarre and persecutory content. The patient was started on haloperidol, and had individual psychotherapy. We met him one year after the onset of the psychotic episode. At that time, he was on haloperidol $5 \mathrm{mg}$ a day. The auditory hallucinations were moderate, but the agoraphobic-like symptoms were unchanged, the patient could make his way to the clinic only if accompanied. After several psychiatric interviews, a treatment by graded in vivo exposure was proposed with 21-h sessions a week. Duration of the outing and distance were gradually increased, and the following situations were successively introduced: use of public transportation accompanied, alone, walking alone at increasing distances. After 8 sessions, the patient could attend the clinic alone and had a quick look at a few shops on the way.
While the summer vacation interrupted the treatment, the patient's parents were instructed about the exposure procedure, and took charge of the sessions during 1 month. After this period Mr L was able to go out alone and use public transport. The medication administered remained unchanged during the therapy. Six month later, improvement is maintained and we are undertaking social skills training.

The very good results obtained at 6-month follow-up encourage systematic studies on the effects of exposure methods for phobias in schizophrenic patients. As other targeted behavioral techniques already used with these patients (Wallace et al, 1980; Liberman, 1985), it could improve their general adjustment by alleviating some of their most invalidating symptoms.

\section{References}

Barlow DH, Wolfe DE (1981) Behavioral approaches to anxiety disorder: a report on NIMH-SUNY, Albany, research conference. Consult Clin Psychol 49, 448-454

Emmelkamp PMG, Kuipers ACM (1979) Agoraphobia: a follow-up study four years after treatment. Br J Psychiatry 134, 352-355

Wallace CJ, Nelson CJ, Liberman RP (1980) A review and critique of social skills training with schizophrenic patients. Schizophr Bull 6, 42-63

Liberman RP (1985) Schizophrenia: psychosocial treatment. In: Comprehensive Textbook of Psychiatry IV (Kaplan HI, Sadock BJ, eds) Williams and Wilkins, Baltimore, ND, 724-734
Christine Sarron François Lelord Paris, France 